achieved in patients with neuropathic incontinence or those incontinent after prostatectomy or injury to the urethra or sphincters. Some patients with epispadias and others who have had radical pelvic surgery may also be helped. The least suitable are women with stress incontinence. ${ }^{8}$ Clearly patients must have sufficient manual dexterity and mental capacity to operate the device.

Initially patients with detrusor hyperreflexia (instability) were rejected, but they may now be helped by the addition of bowel augmentation (for example, ileocaecocolocystoplasty) and sphincter ablation. ${ }^{8}$ If the outflow resistance cannot be lowered sufficiently to match a poorly functioning detrusor an artificial sphincter around the bladder neck may be combined with clean intermittent catheterisation. ${ }^{9}$ This might be particularly applicable in patients undergoing reconstruction of the urinary tract after previous diversion.

This is not an operation for the surgeon who sees the occasional suitable patient. It should be performed only by those few enthusiasts who have the technical knowledge and skill and who are prepared to keep their results under constant review. Highly developed as these present devices are, further advances are inevitable, and surgeons will watch with interest the progress of a magnetic device. ${ }^{10}$ As yet the verdict remains that artificial sphincters are applicable to only a few patients with incontinence and are not always successful.

Consultant Urologist,

R H WHITAKER

Addenbrooke's Hospital

Cambridge CB2 2QQ

1 Kaufman JJ. Treatment of post-prostatectomy urinary incontinence using a silicone gel prosthesis. Br f Urol 1973;45:646-53.

2 Graham SD, Carson CC, Anderson EE. Long-term results with the Kaufman prosthesis. $7 \mathrm{Urol}$ 1982;128:328-30.

3 Scott FB, Bradley WE, Timm GW. Treatment of urinary incontinence by an implantable prosthetic urinary sphincter. $\mathcal{F}$ Urol 1974;112:75-80.

4 Rosen M. A simple artificial implantable sphincter. Br f L'rol 1976;48:675-80.

5 Light JK, Hawila M, Scott FB. Treatment of urinary incontinence in children: the artificial sphincter versus other methods. $\mathcal{F}$ Urol 1983;130:518-21

6 Light JK, Scott FB. Use of the artificial urinary sphincter in spinal cord injury patients. $f$ Urol 1983;130:1127-9.

7 Light JK, Scott FB. The artificial sphincter in children. Br f Urol 1984;56:54-7.

8 Mundy AR, Stephenson TP. Selection of patients for implantation of the Brantley Scott artificial urinary sphincter. Brf Urol 1984;56:717-20.

9 Barrett DM. Furlow WL Incontinence, intermittent self-catheterization and the artificial genitourinary sphincter. $\mathcal{f}$ Urol 1984;132:268-9.

10 Gruneberger AD, Hennig GR. A magnetic urethral closure device: preliminary report of an experimental study. F Urol 1983;130:798-801.

\section{The young patient with a fractured neck of femur}

Fractures of the neck of the femur are common in elderly women and are associated with osteoporosis, which is a feature of the aging skeleton. By contrast, in adults under 50 such fractures are rare, because their bone is dense and hard and it requires considerable violence to break it. Thus in the elderly there is usually history of a trivial injury such as tripping over a carpet or stumbling over a chair, while in young patients there is often high velocity trauma associated with other injuries to the head or abdomen. ${ }^{1}$ Some young adults, however, may suffer fractures from osteopenia resulting from chronic renal failure, treatment with steroids, alcoholism, or other systemic cause, when little precipitating force is required. Such fractures are similar to those in the elderly. ${ }^{2}$

The complications of intracapsular (often called subcapital or transcervical) fractures of the femoral neck in young patients are higher than in the elderly. In a series of 22 young adults in the United States Army non-union occurred in 12 and avascular necrosis in $19 .{ }^{3}$ While in a series of men of whom two thirds were over the age of 65 the proportions were $23 \%$ and $15 \%$. $^{4}$

Avascular necrosis results from interference with the blood supply to the femoral head because of the intracapsular fracture tearing the retinacula, through which the vessels pass from the capsule of the hip joint to the bone. If the blood supply is lost completely the whole of the proximal half of the femoral head (which is the part of the head which corresponds to the original epiphysis) dies. Sometimes avascular necrosis is segmental, and this may be a result of perioperative damage to blood vessels from the screw or nail that is used to fix the fracture. ${ }^{5}$ Patients with avascular necrosis generally have pain on walking, and require secondary operations such as a total hip replacement. These carry a poor long term success rate in younger age groups because of the increased risk of loosening of the prosthesis. ${ }^{6}$

Because fracture of the neck of the femur is relatively rare in young people there are few series to indicate which line of management is best. It has been suggested that these fractures should be regarded as orthopaedic emergencies and every effort made to preserve the blood supply to the femoral head.' Restoration of the blood supply (which has not been destroyed by the injury) may be achieved only by early and accurate reduction of the fracture to straighten kinked vessels and relieve pressure from bony fragments. The results of prompt treatment in a series of 27 patients of mean age 32 years (range 20-49) showed that avascular necrosis occurred in five, which is much lower than in comparable series, which have reported $86 \%{ }^{3}$ and $41 \% .^{7}$ Furthermore, there were no patients with non-union.

Thus, early operation, accurate reduction, and rigid internal fixation is the ideal treatment of a fractured femoral neck in the younger patient. The best method of internal fixation has to be determined, but is likely to be a sliding screw plate. ${ }^{8}$ This ensures compression at the fracture site, but allows for collapse and absorption of bone without the hazard of penetration of the femoral head by the screw, which may slide out of the barrel of the plate if this occurs. Such a device appears to be better than cancellous bone screws or Garden screws. Because accurate reduction of the fracture is important and this may be difficult by a closed procedure, open reduction of the fracture may occasionally be necessary.

In summary, intracapsular fracture of the neck of the femur in patients under 50 demands more experience and technical skill than the same injury in the older patient, where the more severely displaced fractures can usually be treated successfully by inserting a femoral prosthesis.

LESLIE KLENERMAN

Consultant Orthopaedic Surgeon,

Northwick Park Hospital,

Harrow, Middlesex HAl 3 UJ

1 Swiontkowski M, Winquist RA, Hansen ST. Fractures of the femoral neck in patients between the ages of twelve and forty-nine years. $\mathcal{J}$ Bone foint Surg 1984;66A:837-46.

2 Zetterberg $\mathrm{CH}$, Irstam L, Anderson GBJ. Femoral neck fractures in young adults. Acta Orthop Scand 1982;53:427-35.

3 Protzman RR, Burkhalter MD. Femoral neck fracture in young adults. I Bone foint Surg 1976;58A:689-94.

4 Barnes R, Brown JT, Garden RS, Nicoll EA. Subcapital fractures of the femur. $\mathcal{J}$ Bone Joint Surg 1976;58B:2-24.

5 Wilson JN, ed. Watson-fones fractures and joint injuries. Edinburgh: Churchill Livingstone, 1982 :

6 Chandler HP, Reineck FT, Wilson RI, McCarthy JC. Total hip replacement in patient younger than thirty years old. $\mathcal{J}$ Bone Joint Surg 1981;63A:1426-34.

7 Kofoed H. Femoral neck fractures in young adults. Injury 1982;14:146-50.

8 Fielding JW, Wilson SA, Ratzan S. A continuing end-result study of displaced intracapsular fractures of the neck of the femur treated with the Pugh nail. $\mathcal{J}$ Bone foint Surg 1974;56A 1464-72. 